\title{
Of Rainbow Unicorns \\ The Role of Bonding Queer Icons in Contemporary LGBTIQ+ Re-Positionings
}

\section{Giuseppe Balirano}

Dipartimento di Studi Letterari, Linguistici e Comparati, Università degli Studi di Napoli "L'Orientale" gbalirano@unior.it

<http://docenti2.unior.it/index2.php?user_id=gbalirano\&content_id_start=1>

\begin{abstract}
Over the years, queer icons have in the main displayed a dual yet conflicting function: that of cautiously dissimulating reality, while blatantly representing it. This ambiguous play, with its geographical limits and contextual caveats, has provided LGBTIQ+ communities with spaces for the re-appropriation and abrogation of a number of male hegemonic imperatives. This line of action has, however, led to an idiosyncratic positioning since such a political practice may merely represent another marginal stance due to the persisting relation to the hegemonic itself. This paper, while analysing the proliferation of so-called queer iconic objects, will discuss the emerging concept of "bonding icons" and their inscription within an affiliation system as the active community enhancers of the new queer political agenda. The resulting resemiotised discourses seem to re-construct the queer "other" in various ways by reifying it into a similar and relatable "other" whose iconicity is able to provide reassurance and validation while evoking universal empathetic alignment.
\end{abstract}

\section{Keywords}

Bonding queer icons; Affiliation systems; Systemic functional linguistics; Coupling

\section{Sommario/Content}

1. Introduction

2. Queer iconicity

3. Bonding queer icons and the negotiation of coupling

4. Discussion

5. Conclusion

References 


\section{Ocula}

Vol 21, No 22 (April 2020) • DOI: 10.12977/ocula2020-7

Giuseppe Balirano | Of Rainbow Unicorns. The Role of Bonding Queer Icons

in Contemporary LGBTIQ+Re-Positionings

\section{Introduction}

Social semiotic scholars have often investigated the role played by transnational media in disseminating Western values and goods with the purpose of fashioning, moulding or re-constructing global and homogeneous identities (cf. Machin and Van Leeuwen 2003, 2004, 2005; Machin 2004). The tie-in between global consumerism and the widespread reproduction of invariant ideas and signs, often conveying covert forms of subjugation, inevitably leads to a systematic uniformity in identity construction. Moreover, the rapid contemporary advances in digital connectivity are increasingly facilitating the spread of unifying signs, such as Internet memes, which inevitably attain viral circulation. A vast array of consumer goods and services, from beauty products, home security systems, designer clothing, to exotic perfumes, sex toys, and sex apps, to name but a few, are now part of the worldwide domestic economy and consequently contribute to the shaping of our present-day globalised body of knowledge (cf. Milani 2018). The ads promoting the use of such commodities, and the real or virtual places where they can be purchased or used - from shopping centres to digital websites - have also become ever more pervasive. However, given the nature of the items, the discourses they produce and around which they revolve within capitalistic and consumeristic practice, they may also emerge as potential sites of resistance and, more specifically, the discursive loci where the Foucauldian notion of 'subjugated knowledges' (cf. Foucault 1980b, 1987a) can easily be observed. French philosopher Michel Foucault claimed in a number of lectures and interviews that certain bodies of knowledge can become subjugated by more powerful actors. Indeed, commodification practices, by standardising specific worldviews, may also cause the formation of spaces where the less powerful - those not included in mainstream culture - can be relegated (cf. Foucault 1980b, 1987a). The dissenting views of those with alternative life experiences are thus actively excluded from mainstream discourses since they are never really taken into consideration by the media, and as a result, they become "subjugated". Foucault (1980b: 81-82) maintains that such forms of subjugation represent the expression of (a) «the historical contents that have been buried and disguised in a functionalist coherence of formal systematisation", allowing the understanding of «the ruptural effects of conflict and struggle» that are masked by the order of «functionalist or systematising thought»; and (b) the "whole set of knowledges that have been disqualified as inadequate to their task or insufficiently elaborated: naive knowledges, located low down on the hierarchy». Both features of subjugated knowledges are inexorably connected to power and, more importantly, to "a historical knowledge of struggles» (Foucault 1980b: 82).

As such, subjugated knowledges always represent, at a specific time and in a given culture, an expression of resistance that is typically embodied by certain objects. The body itself, for instance, or, as Foucault (1980a, 1987b) has repeatedly highlighted, the quintessential expression of power and knowledge, stands for a prime manifestation of subjugated knowledges. As a potential site 


\section{Ocula}

Vol 21, No 22 (April 2020) • DOI: 10.12977/ocula2020-7

Giuseppe Balirano | Of Rainbow Unicorns. The Role of Bonding Queer Icons

in Contemporary LGBTIQ+Re-Positionings

of pleasure and resistance, the body and the vast constellation of attributes referred to it, must, however, not be solely understood as the mere physical display of personhood, but also as the place around which given discourses and counter-discourses are built. Such a body (of knowledge) thus represents a site for practices to be shaped and construed. The body or, more broadly, the specific signs that are expressive of such a physical frame, may be regarded as repositories and, at the same time, producers of knowledge through the acquisition and reproduction of practices (Foucault 1980a). This is particularly true when it comes to gay bodies and gay objects that channel and enhance the representations of a specific community (Lahti 1998). Indeed, as Dyer (1992: 169) maintains, "many aspects of gay culture are a body culture, discovering and constructing new possibilities for the body», thus creating and engendering potentiality for new forms of knowledge. In this way, the body within gay culture and the discourses that elect it as an object of knowledge may become the basis for the creation of counter-discourses and, thus, potential sites of resistance where «an amorphous atmospheric continuum» (Deleuze and Guattari 1987: 112) can easily materialise. Indeed, as Foucault (1987a: 101-102) argues, «there is not, on the one side, a discourse of power, and opposite it, another discourse that runs counter to it [...]. [...] [Discourses] can circulate without changing their form from one strategy to another, opposing strategy». That is, power must never be regarded from a holistic perspective since it always creates fractures, where potential resistance may be engendered: «[p]ower, after investing itself in the body, finds itself exposed to a counter-attack in that same body» (Foucault 1980a: 56). Therefore, once power has found an object through which it can be exercised, that locus becomes a site for struggle or emancipation. At the same time, however, once such a form of counter-discourse has progressively lost its charge and been appropriated by mainstream culture, it may then in turn become a locus for the reproduction of other forms of power. Hence, the circularity of the discursive construction and exercise of power vs counter-power is maintained.

In line with the observations provided in the previous paragraphs, the following paper investigates how subjugated gay identities embodied in/by queer icons, as specific forms of counter-discourse, may travel across cultures, space and gender to construct and/or mix with other identities to eventually become other social and cultural sites (Orlando 2006). Gay pride parades, for instance, ignited by the Stonewall riots, have fostered the insurrection of yet another form of subjugated knowledge and the official depathologisation of homosexuality in a common fight against homophobia. Against this backdrop, I will introduce the novel concept of "bonding queer icons", to finally delve into the analysis of some queer iconic representations.

\section{Queer iconicity}

Throughout this study, I will use the term "icon" exclusively to denote those images, logos, pictures, places, famous people, particular events or situations, or other ensuing items or ideas that have had a long-lasting incidence 


\section{Ocula ${ }^{22}$}

Vol 21, No 22 (April 2020) • DOI: 10.12977/ocula2020-7

Giuseppe Balirano | Of Rainbow Unicorns. The Role of Bonding Queer Icons

in Contemporary LGBTIQ+Re-Positionings

on wide and distinct communities. In particular, the icons under scrutiny here are cultural artefacts that are immediately familiar to a large number of people since they exemplify a concept or an idea that has significant cultural implications for the construction of a collective identity. "Cultural icons", as Fiorentino (2009: 9) defines them, tend to become part of a symbolic and cultural heritage which language and discourses draw upon. They represent community symbols, collective stories, societal discourses or even social practices which, displaced from their original contexts, may be re-inscribed and operate independently in a variety of other settings giving rise to other stories while acquiring new life. Cultural icons can, in fact, travel easily from one place to another, gradually taking on new meanings through a lengthy process of revitalisation. Through complex practices of resemiotisation and remediation, without ever changing their form though, they represent forms of knowledge and embody definite discourses that can circulate widely as both societal and media processes unfold. The image of the handsome Christian saint, Sebastian, for instance, has frequently been resemiotised as a prototypical gay icon. Although throughout the history of Sebastian's martyrdom, there was nothing that might have hinted at the saint's homosexuality, Saint Sebastian has always been portrayed as a desirable, half-naked, smooth-chested young man whose ephebic body has been pierced by several arrows. Sebastian's alleged homosexuality, therefore, is a clear example of the way iconogenesis can be triggered by other signs while insinuating further narratives devoid of origin or end. The Italian Renaissance painters shunned the adult and hirsute saint of medieval iconography, and emphasised one single detail of the young saint's body: his pierced torso which eventually gave rise to other forms of knowledge where new narratives could be created and particular discursive practices enhanced. Subsequently, several modern writers remediated the queer religious icon by employing the name Sebastian to slyly ascribe an ambiguous sexuality to some of their characters, such as Sebastian in Brideshead Revisited by Evelyn Waugh (1945), or his namesake in Suddenly, Last Summer by Tennessee Williams (1958). Likewise, Oscar Wilde chose the name Sebastian as his pseudonym after being released from prison. Yet another interesting form of iconic remediation is to be found in the biographical film Sebastiane (1976) directed by the independent British film-director Derek Jarman (see Vigo and Rimini 2018). Consequently, the slow but steady image-construction of this queered icon has spread into mainstream milieus, and while possibly detracting from an understanding of what "normal" gay identities are, it has offered a supportive representation of queerness through the saint's legitimating role.

While originally the term "icon" designated a religious image, generally painted or carved on wood, and used for worshipping deities, over the last two centuries, icons have slowly come to be associated with the multiple and interwoven signs of profane global culture. The function of global contemporary secular iconicity is to construct or represent a collective identity by appropriating and renovating the pre-existent ideas, beliefs, and interests of a given community. This appropriation technique has often provided the LGBTIQ+ community, in particular, with «challenging, even confrontational, ways of subverting 


\section{Ocula}

Vol 21, No 22 (April 2020) • DOI: 10.12977/ocula2020-7

Giuseppe Balirano | Of Rainbow Unicorns. The Role of Bonding Queer Icons

in Contemporary LGBTIQ+Re-Positionings

mainstream culture and inserting their own odd, even perverse perspectives on a largely unsuspecting and often unsuspicious public» (Cooper 1996: 14). According to Mathieu, this practice of destabilising mainstream culture via gay iconography is expected to queer society as a whole:

[T] his "queerness" is not only based on content (gay iconography, sexual innuendoes, phallic forms, etc.) although at times it is one of the strategies employed. But it also, and more importantly, makes use of queer concepts, such as humour and camp, inversion, and reversal, excess and extremes, in an irreverent attitude to conventions and social prescriptions, a subversive approach to systems. (Mathieu 2003: 93)

Traditionally, LGBTIQ+ people used to misidentify exclusively with popular straight female artists, or divas, in order to have a room of their own in pop culture where, as subjugated objects, they had never been fully represented. Harris (1997: 10), indeed, explains that «at the very heart of gay diva worship is not the diva herself but the almost universal homosexual experience of ostracism and insecurity». The gay community, therefore, iconises heterosexual female performers such as Judy Garland, May West, Liza Minnelli, Cher, Madonna, Britney Spears, Whitney Houston, Amy Winehouse, Lady Gaga, etc., only because there has been so little community representation in the greater mediascape through which a fully-fledged gay identity could have been built. Some of these iconic women are elected as testimonials of a subjugated culture since they themselves have suffered, been exploited, damaged or, in the worst cases, destroyed by stardom power struggles. Georges-Claude Guilbert in his seminal book Gay Icons: The (Mostly) Female Entertainers Gay Men Love offers a clear account of female gay icons:

The gay icon tends to be heterosexual. Sometimes she is a fighter, sometimes a long-suffering victim; in any case, she's a strong personality, who often ends tragically. She is a star, and no one becomes a star without encountering some pitfalls on the way. The fighter gay icon has learned to defend herself, to fight for her rights and her freedom. (Guilbert 2018: 6)

Whenever queer forms of expression have been limited and subjugated by the power struggles pertaining to heteronormative discourses, these straight gay-icons have come to embody forms of counter-discourse. The fact that they have been singled out to represent and, more importantly, embody projected subjugated knowledges has led to the creation of other forms of resistance. These icons, therefore, are not only considered the expression of queerness per se but can also be seen as the projection of a queer political agenda that mainstream tradition has enabled.

Queer historian Halperin (quoted in Staples 2019, n.p.) aptly describes the attitude of the gay world towards prominent mainstream gay men as being «highly critical, if not contemptuous, of their own artists, writers and filmmakers». He maintains, for instance, that gay communities have often rejected gay characters since they «don't often like the representations of gay men 


\section{Ocula}

Vol 21, No 22 (April 2020) • DOI: 10.12977/ocula2020-7

Giuseppe Balirano | Of Rainbow Unicorns. The Role of Bonding Queer Icons

in Contemporary LGBTIQ+Re-Positionings

that gay men produce» (Halperin as quoted in Staples 2019, n.p.). He further specifies that this is mainly due to the fact that most mainstream representations of gay men tend to produce and reproduce normative heterosexual practices. Halperin, therefore, identifies, on the one hand, a conventional gay culture, where white gay men are dominant; and on the other, a gay subculture, where women, drag queens, black and trans people tend to have more visibility. In other words, the embodiment in an icon of given discourses and practices generates fractures and dichotomies related to the ways in which such a symbol epitomises certain values and forms of representation. This distinction triggers the refusal, by the gay community, of gay cultural icons identified as normative heterosexual representations, and grants credence to the idea that the community's increased visibility now allows it to shed these straight cultural figures as community icons. The enduring prominence the LGBTIQ+ community, however, shows that there is still a lot to be done.

A number of scholarly publications have investigated the role of female divas as queer icons (see Guilbert 2018, for a detailed account), mainly highlighting the function and attributes of these diva performers in the gay world. The types of queer icons this study intends to investigate pertain to the category of objects, concepts and events which seem to have travelled far and wide and crossed distant cultures. These cultural icons work in two different directions: (1) they strengthen and spread queer discourses of belonging and community building, while (2) crossing the borders of gendered representations to be employed and re-used by everybody, irrespective of their sexual orientation. ${ }^{1}$ The queer icons under scrutiny here are associated with the representation of the gay body and its ability to reproduce both power and counter-power. These icons are, in fact, primarily made to grant pleasure to the body, to make it aware of its intrinsic power and to popularise its multifaceted discourse(s). Philosophical, feminist and poststructuralist debates around the body (Foucault 1980a, 1987a; Bartky 1988; Bordo 1989; Grosz 1994) have established that our knowledge of the body and, indeed, the body itself are rooted in specific cultural and historical conditions and in the context of particular relations of power. As observed in the introductory section of this paper, it is the gay body which has met with an unparalleled proliferation of iconic attributes, a reflection and, sometimes, a projection of its materiality that may then be associated with the (re)production of power, to forms of counter-power or even to novel "subjugated knowledges". In other words, the interest of this paper is mainly related to «how the person who is disabled through one set of oppressions may by the same positioning be enabled through others» (Sedgwick 1993: 328).

1 This is the reason why I shall be referring to them throughout this paper as queer icons. By using the term "queer" I am not indeed referring to all those people who self-identify as "queer" and, therefore, I am not linking such icons as forms of expression only related to them. I am using the term to refer to all those "objects" denoting or relating in a specific way to sexual or gender identities that do not necessarily correspond to established heteronormative ideas of sexuality and gender representation. 


\section{Ocula ${ }^{22}$}

Vol 21, No 22 (April 2020) • DOI: 10.12977/ocula2020-7

Giuseppe Balirano | Of Rainbow Unicorns. The Role of Bonding Queer Icons

in Contemporary LGBTIQ+Re-Positionings

\section{Bonding queer icons and the negotiation of coupling}

In this section, I will briefly outline the concept of "bonding queer icons" and the way it relates to the previously introduced notion of "cultural icons" by distancing my research from what has been extensively studied, in semiotic investigation, by Charles Sanders Peirce, since the 1860 s.

A preliminary definition of "bonding icons" sees them as evocative objects, symbols or places of social belonging that draw people into shared or imagined communities. More specifically, according to Stenglin (2004, 2009, 2011, 2012), icons are signs, multi-dimensional in nature, which can constitute a range of different things. In the case of queer icons, the range is extensive and may include:

a) OBJECTS, certain items have become queer icons such as the colourful AussieBum or Andrew Christian underwear, or Dorothy's ruby slippers from The Wizard of $\mathrm{Oz}$ (1939), etc.;

b) SYMBOLS, like the rainbow flag or the pink triangle, the latter being a symbol for various LGBTIQ+ identities, initially intended as a badge of shame, but later reclaimed as a positive symbol of self-identity;

c) PLACES or EVENT, such as Stonewall, the Greenwich Village in New York, or more broadly gay pride parades, and more recently RuPaul's Drag Race and DragCon.

All bonding icons are able to symbiotically combine M.A.K. Halliday's ideational and interpersonal metafunctions (Halliday 1978). In linguistics, in fact, we explore ideational meanings taking into account the register variable of field (Halliday 1978, 1985; Martin 1992). This variable consists of two experientially distinct dimensions: "activity sequences" and the "things" they contain. Therefore, in adopting a social semiotic approach to queer icons, I will consider how interpersonal meaning combines with ideational meaning in a specific queer icon: the rainbow or pink, glitter unicorn. I will consider the ideational meaning of this icon, which openly discloses the instability of today's societies by challenging heteronormative power and values, while at the same time providing a marginal status for LGBTIQ+ individuals.

The theoretical basis of this approach is the linguistic concept of "coupling" introduced by Martin (2000) and then further developed by Zappavigna, Dwyer and Martin (2008) and Zhao $(2010,2011)$ in order to look at textual relations. In Zhao's words, coupling involves the association of different semiotic elements in the construction of the meaning-making process:

Coupling concerns the temporal relation of 'with': variable x comes with variable $y$. To put it another way, it is the relation formed between two semiotic elements at one given point in time within the logogenetic timeframe. Coupling can be formed between metafunctional variables (e.g. ideational and interpersonal), between different semiotic resources (e.g. image and verbiage) and across strata (e.g. semantics and phonology). (Zhao 2011: 144)

Such a notion may thus easily be applied to the investigation of cultural icons by looking at the types of relations they enact in society; that is, how 


\section{Ocula}

Vol 21, No 22 (April 2020) • DOI: 10.12977/ocula2020-7

Giuseppe Balirano | Of Rainbow Unicorns. The Role of Bonding Queer Icons

in Contemporary LGBTIQ+Re-Positionings

communities build through their own icons other semiotic and discursive loci where their members can commune, negotiate or reject the value sets they construe. According to Knight (2010: 43), «we discursively negotiate our communal identities through bonds that we can share, and these bonds make up the value sets of our communities and culture, but they are not stable and fixed». In other words, in order to align (or disalign) ourselves with a specific set of values or evaluative stances towards given discursive representations, attitudes about people, places, things, etc. must be construed (Zappavigna 2014, 2019). Such a fundamental concept can therefore be used to explore how values are discursively construed and enhanced in combination with expressions of evaluation.

Coupling is, therefore, seminal to understanding how these processes of association among entities, values and stances interact to create bonds. According to Martin (2008: 39), coupling refers to «the ways in which meanings combine, as pairs, triplets, quadruplets or any number of coordinated choices from system networks». This way, specific linguistic and, more generally, semiotic patterns can be highlighted in different texts and discourses that can be used to combine interpersonal and experiential meanings as associations of ideation and attitude (Zappavigna 2019). Such forms of co-selection may engender the creation of interactive social bonds, that is, discursive entities whose recurrent associations to given types of evaluation lead to specific interpersonal and experiential meanings that individuals see themselves aligning with, or distancing from. Such a discursive process may, of course, be conveyed both textually and through other forms of semiotic communication. Additionally, once the coupling between these different levels has been enacted, affiliation is then enabled. Affiliation means that people can commune around something with very explicit stances, be they negative or positive. Affiliation can occur both when individuals interact and commune directly (in this case, it is usually referred to as "dialogic affiliation"), but also when people commune around a specific discursive item, but do not interact directly (in this case, it is known as "communing affiliation"; see Zappavigna and Martin 2018; Zappavigna 2018). In the latter case, in order for this to occur, individuals need specific engagement systems represented by given entities which, in our specific case, can indeed be represented by cultural icons. Much like in social media, where hashtags become affiliation systems thanks to which people can commune around given discursive representations, icons may be seen as the embodiment of discursive representations that allow people to interact with one another without necessarily engaging in a direct encounter. They become instruments of negotiation and, sometimes, of discursive resistance towards dominant ideologies. In the next section, I will analyse a particular bonding icon relating specifically to the LGBTIQ+ community.

\section{Discussion}

The bonding queer icon under scrutiny in this paper is the legendary unicorn. Why the unicorn should become a bonding queer icon is easy to understand. Unicorns have represented otherness, freedom and transformative 


\section{Ocula}

Vol 21, No 22 (April 2020) • DOI: 10.12977/ocula2020-7

Giuseppe Balirano | Of Rainbow Unicorns. The Role of Bonding Queer Icons

in Contemporary LGBTIQ+Re-Positionings

power since the $16^{\text {th }}$ and $17^{\text {th }}$ centuries (see Hamilton 2005). Thanks to their gender fluidity, alongside other mythical creatures, unicorns have been secretly representing bisexual people as far back as Queen Elizabeth I; they were also directly involved in the creation of the so-called Victorian unicorn porn, as part of the process of elaborating class identity. Moreover, unicorns gained a reputation for being elusive since nobody could ever quite see or catch them as if they led different lives simultaneously situated in parallel worlds. In a similar manner, LGBTIQ+ individuals have always felt as if they only partially belonged to the society they live in since their very existence has often blurred, with several difficulties, the heteronormative boundaries. The unicorns' mystical powers and their innate representation of "otherness", have recently attracted the queer gaze. Fantastic creatures imbued with mystical powers whose bodies that simultaneously incarnate the real and unreal cannot but instantly become iconic in representing the shared feelings of community members.

As regards affiliation, in order to claim unicorns as a representation of the LGBTIQ+ community, other semiotic systems of representation need to be called into play. The queer unicorn mane, for instance, bears the multi-hued colours of the rainbow flag, thus underlining the connection and appropriation of the icon by the LGBTIQ+ community. The rainbow flag, created by American artist Gilbert Baker in 1978 as a symbol of the diversity of the LGBTIQ+ community, became well known during the gay rights protests of the 1970 s and 1980 s. Rainbows and unicorns frequently bond together especially on banners at Gay Pride Parades around the world, where slogans such as "Gender is Imaginary" or "Totally Straight" are accompanied by sparkling rainbow unicorns (Fisher 2017).

The American singer, songwriter, actor, director, choreographer and YouTuber Todrick Hall, for instance, in his music video Dem Beats (2018), appears in full unicorn drag prancing around the stage half-naked. More specifically, in the very first frame of the video, he queers the scene by sporting very high heels in the shape of unicorn hooves. The queer body of the human unicorn brings into being a novel multiform sign which can be gazed at as both the new repository and the producer of knowledge by means of the reproduction of separate pre-existing discourses. In the video, the camera moves up quickly to reveal that the represented participant - that is, Todrick Hall in drag - is wearing clothes and accessories that allow him to look like a living human unicorn. The cosplay outfit contests heteronormative boundaries and binaries to an even greater extent and the resulting new queer icon is employed to challenge and question the binary opposition between masculinity and femininity, reclaiming a space of self-expression and freedom. The drag unicorn is semiotically construed as a gender-fluid social actor who, through the criticising lyrics of the song (they don't make dem beats like they used to), denounces the way gay music is negatively changing by gradually going mainstream. In the video, both the representation of the experiential world (i.e. representational meaning) and the interaction between the participants who form a choreographed visual design and the viewers (i.e. interactive meaning) are simultaneously at 


\section{Ocula $^{22}$}

Vol 21, No 22 (April 2020) • DOI: 10.12977/ocula2020-7

Giuseppe Balirano | Of Rainbow Unicorns. The Role of Bonding Queer Icons

in Contemporary LGBTIQ+Re-Positionings

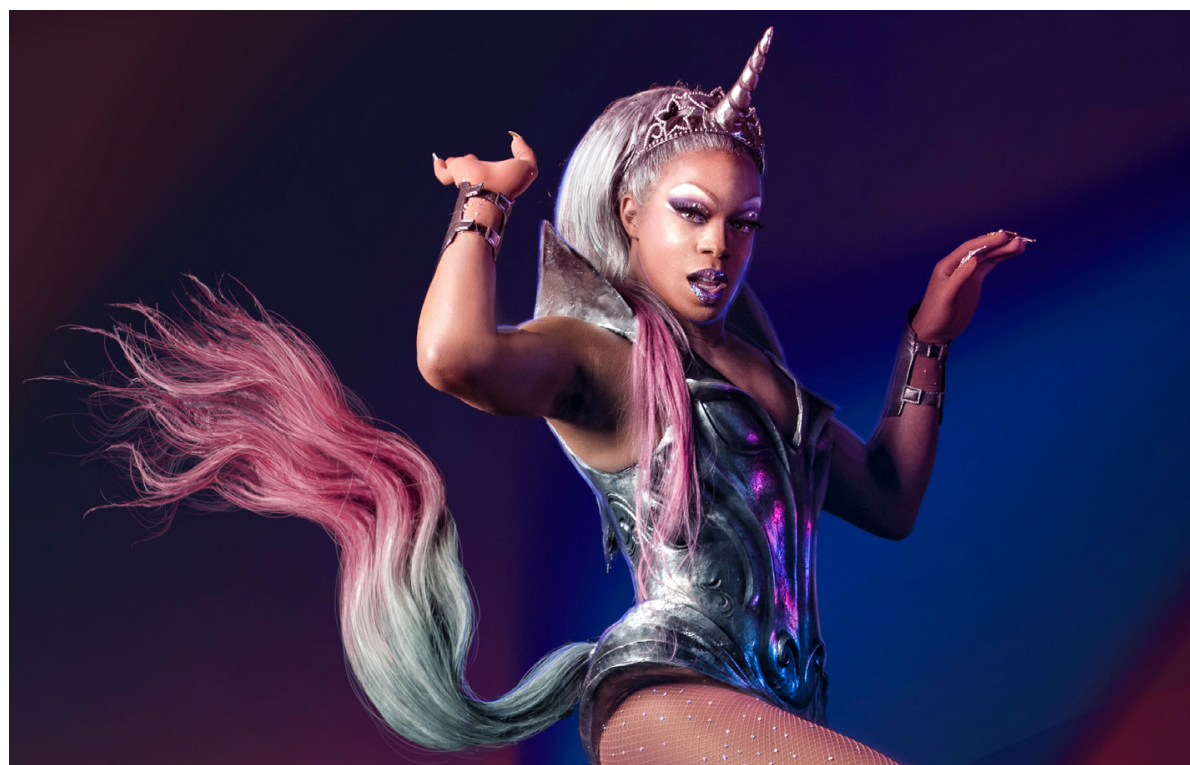

Figure 1. Todrick Hall's Drag Unicorn.
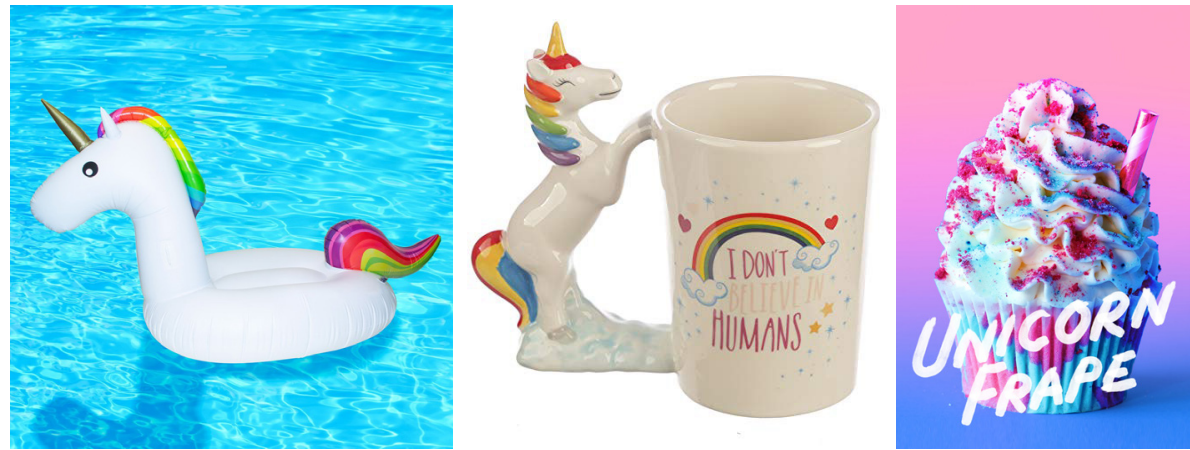

Figure 2. Examples of the unicorn icon as consumer good.

play: the represented participant's direct gaze engages with the audience and $\mathrm{s} /$ he is always situated above the audience, in a position of privilege and superiority. The video projects a strong image of power which, despite the phallic horn on the head of the represented participant, succeeds in playing with gender fluidity in an interesting non-binary and intersectional manner.

In recent years, unicorns have progressively become mainstream representations bestowing agency onto their audiences and firmly situating their creative output within the logics of commodity culture. In summertime, we can now observe inflatable pink or rainbow-hued unicorns riding the waves or drifting across swimming pools. Instagram posts, stories and videos, depicting these inflatable creatures are trending, and the audience does not necessarily belong to the LGBTIQ+ community. Teacups and other accessories now display iconic representations of unicorns. Two years ago, Starbucks launched the Unicorn frappuccino and rainbow-hued unicorn toast and cakes have be- 


\section{Ocula}

Vol 21, No 22 (April 2020) • DOI: 10.12977/ocula2020-7

Giuseppe Balirano | Of Rainbow Unicorns. The Role of Bonding Queer Icons

in Contemporary LGBTIQ+Re-Positionings

come a major food trend. In the beauty community, unicorn hair, unicorn nails and glittery body gel known as Unicorn Snot are all the rage. The unicorn icon, across time and space, has clearly taken up other signs to form a network of signs of signs in a limitlessness of significance which projects its shadow onto an amorphous atmospheric continuum.

\section{Conclusion}

As discussed, the LGBTIQ+ community has identified in elected queer icons a way to allow its members to increase their visibility by participating in processes of shared identity construction that challenge the very notion of subjugated knowledges. Some of these icons, however, have gradually become mainstream, thus forfeiting the global political charge which enabled them to resist specific forms of the hegemonic. Affiliation systems that elect bonding icons as their main discursive tool to challenge the traditional relegation of the community to a separate or marginal space, originally claimed a space for the re-appropriation and abrogation of a number of male hegemonic imperatives leading to an idiosyncratic positioning. However, this practice may be seen to merely represent another marginal stance in relation to the hegemonic itself. For if, on the one hand, it is true that the proliferation of so-called queer icons has provided a space for the creation of affiliation systems as active community enhancers of the new queer political agenda, on the other hand, queer icons have also been appropriated by mainstream culture, often within a neoliberal framework. This has favoured an iconic functional shift, from artefacts laying claim to cultural rights, to icons that have become an easy expedient to promote gadgets, sponsor goods and, overall, obtain full participation in the commodification process; and, as is often the case, consumerist culture seems to erase or, at least, mitigate their original counter-discursive nature. This way, subjugated knowledges become part of the capitalistic economic system, reproducing and enhancing commodified values that were initially only relegated to a group minority. This could generate a continuous reversal process where cultural and iconic re-appropriation seems to be a common practice. A new CBS sitcom, for instance, titled The Unicorn (2019), features a heterosexual male who becomes the eligible bachelor due to his widowed father status. Or, the recent film Unicorn Store (2017) on Netflix, which seems to have a similar heterosexual vibe suggesting a sort of heteronormative re-appropriation of the analysed bonding icon.

This paper has analysed the formation of so-called queer icons by probing the linguistic theory of "bonding icons" applied to semiotic studies. It has then investigated the unicorn as a queer icon and its initial inscription within the affiliation system of the new queer political agenda. The case of the unicorn as a bonding queer icon is symptomatic of the manner in which a value-laden object representing a community's subjugated knowledges can be exploited by the capitalistic apparatus system and turned into a mere gadget devoid of any political significance. As societies and value systems change, what was once appreciated and worshipped can progressively become redundant, or even 


\section{Ocula}

Vol 21, No 22 (April 2020) • DOI: 10.12977/ocula2020-7

Giuseppe Balirano | Of Rainbow Unicorns. The Role of Bonding Queer Icons

in Contemporary LGBTIQ+Re-Positionings

embarrassing for a community's collective self-image. For the LGBTIQ+ community, such a change in attitude very often seems to occur on a generational basis and, thus, it needs to be accepted.

\section{References}

Bartky, Sandra L.

1988 "Foucault, Femininity and the Modernization of Patriarchal Power", in Diamond, I. and Quinby, L. (eds.), Feminism and Foucault: Reflections on Resistance, Boston (MA), Northeastern University Press, pp. 61-86.

Bordo, Susan

1989 "The Body and the Reproduction of Femininity: A Feminist Appropriation of Foucault”, in Jaggar, A.M. and Bordo, S. (eds.), Gender/Body/Knowledge: Feminist Constructions of Being and Knowing, New Brunswick (NJ), Rutgers University Press, pp. 165-184.

Cooper, Emmanuel

1996 “Queer Spectacles”, in Horne, P. and Lewis, R. (eds.), Outlooks: Lesbian and Gay Sexualities and Visual Cultures, London, Routledge, pp. 13-27.

Deleuze, Gilles and Guattari, Félix

1987 A Thousand Plateaus: Capitalism and Schizophrenia, Minneapolis, University of Minnesota Press.

Dyer, Richard

1992 Only Entertainment, London and New York, Routledge, 2002².

Fiorentino, Francesco

2009 Icone Culturali d'Europa, Macerata, Quodlibet.

Fisher, Alice

2017 "Why the Unicorn has Become the Emblem for our Times" (October 15), The Guardian, retrieved December 12, 2019, from <https://www.theguardian.com/ society/2017/oct/15/return-of-the-unicorn-the-magical-beast-of-our-times $\geq$.

Foucault, Michel

1980a "Body/Power. Interview", in Gordon, C. (ed.), Power/Knowledge: Selected Interviews and Other Writings 1972-1977, New York (NY), Pantheon Books, pp. 55-62.

1980b “Two Lectures”, in Gordon, C. (ed.), Power/Knowledge: Selected Interviews and Other Writings 1972-1977, New York (NY), Pantheon Books, pp. 78-108. 1987a Discipline and Punish: The Birth of the Prison, London, Penguin.

1987b The History of Sexuality: An Introduction, Harmondsworth, Penguin.

Grosz, Elizabeth A.

1994 Volatile Bodies: Toward a Corporeal Feminism, St Leonards (NSW, Australia), Allen \& Unwin.

Guilbert, Georges-Claude

2018 Gay Icons: The (Mostly) Female Entertainers Gay Men Love, Jefferson (NC), McFarland \& Company. 


\section{Ocula}

Vol 21, No 22 (April 2020) • DOI: 10.12977/ocula2020-7

Giuseppe Balirano | Of Rainbow Unicorns. The Role of Bonding Queer Icons

in Contemporary LGBTIQ+Re-Positionings

Halliday, Michael A.K.

1978 Language as Social Semiotic: The Social Interpretation of Language and Meaning, London, Edward Arnold.

1985 An Introduction to Functional Grammar, London, Arnold.

Hamilton, John

2005 Unicorns and Other Magical Creatures, Minnesota, ABDO Publishing Company.

Harris, Daniel

1997 The Rise and Fall of Gay Culture, New York (NY), Hyperion.

Knight, Naomi K.

2010 "Wrinkling Complexity: Concepts of Identity and Affiliation in Humour", in Bednarek, M. and Martin, J.R. (eds.), New Discourse on Language: Functional Perspectives on Multimodality, Identity, and Affiliation, London, Continuum, pp. 35-58.

Lahti, Martti

1998 "Dressing Up in Power: Tom of Finland and Gay Male Body Politics", Journal of Homosexuality, 35/3-4, pp. 185-205, DOI: 10.1300/Jo82v35no3_o8.

Machin, David

2004 "Building the World's Visual Language: The Increasing Global Importance of Image Banks in Corporate Media”, Visual Communication, 3/3, pp. 316-336.

Machin, David and van Leeuwen, Theo

2003 "Global Schemas and Local Discourses in Cosmopolitan", Journal of Sociolinguistics, 7/4, pp. 493-512.

2004 "Global Media: Generic Homogeneity and Discursive Diversity", Continuum: Journal of Media \& Cultural Studies, 18/1, pp. 99-120.

2005 "Language Style and Lifestyle: The Case of a Global Magazine", Media, Culture \& Society, 27/4, pp. 577-60o.

Martin, James R.

1992 English Text: System and Structure, Amsterdam and Philadelphia, John Benjamins Publishing Company.

2000 "Beyond Exchange: APPRAISAL Systems in English", in Hunston, S. and Thompson, G. (eds.), Evaluation in Text: Authorial Stance and the Construction of Discourse, Oxford, Oxford University Press, pp. 142-175.

2008 "Tenderness: Realisation and Instantiation in a Botswanan Town", Odense Working Papers in Language and Communication, 29, pp. 30-58.

Mathieu, Paul

2003 Sex Pots: Eroticism in Ceramics, New Brunswick (NJ), Rutgers University Press.

Milani, Tommaso M.

2018 "Is the Rectum a Gold Mine? Queer Theory, Consumer Masculinities, and Capital Pleasures”, in Baker, P. and Balirano, G. (eds.), Queering Masculinities in Language and Culture, London, Palgrave Macmillan, pp. 19-42.

Orlando, Francesco

2006 Obsolete Objects in the Literary Imagination: Ruins, Relics, Rarities, Rubbish, Uninhabited Places, and Hidden Treasures, translated by Gabriel Pihas, Daniel Seidel, and Alessandra Grego, New Haven, Yale University Press. 


\section{Ocula ${ }^{22}$}

Vol 21, No 22 (April 2020) • DOI: 10.12977/ocula2020-7

Giuseppe Balirano | Of Rainbow Unicorns. The Role of Bonding Queer Icons

in Contemporary LGBTIQ+Re-Positionings

Sedgwick, Eve K.

1993 "Axiomatic", in During, S. (ed.), The Cultural Studies Reader, London and New York, Routledge, pp. 320-339, 1999².

Staples, Louis

2019 "Why Is Judy Garland the Ultimate Gay Icon?” (September 24), BBC News, retrieved October 10, 2019, from <http://www.bbc.com/culture/ story/20190923-why-is-judy-garland-the-ultimate-gay-icon $\geq$.

Stenglin, Maree

2004 Packaging Curiosities: Towards a Grammar of Three-Dimensional Space, Unpublished Doctoral Dissertation, Sydney, University of Sydney, retrieved April 23, 2019, from <https://ses.library.usyd.edu.au/bitstream/2123/635/2/ adt-NU20050909.16134301front.pdf $>$.

2009 "Space Odyssey: Towards a Social Semiotic Model of 3D Space”, Visual Communication, 8/1, pp. 35-64.

2011 "Interpersonal Meaning in 3D Space: How a Bonding Icon Gets Its 'Charge", in Unsworth, L. (ed.), Multimodal Semiotics: Functional Analysis in Contexts of Education, London and New York, Continuum, pp. 50-66.

2012 “"Glocalisation': Exploring the Dialectic between the Local and the Global”, in Bowcher, W.L. (ed.), Multimodal Texts from Around the World: Cultural and Linguistic Insights, London, Palgrave Macmillan, pp. 123-145.

Vigo, Francesca; Rimini, Stefania

2018 "Perspectives of the Male Nude: Queerness and Masculinity in Derek Jarman's Films", in Balirano, G. and Palusci, O. (eds.), Miss Man? Languaging Gendered Bodies, Newcastle upon Tyne, Cambridge Scholars Publishing, pp. 133-153.

Zappavigna, Michele

2014 "CoffeeTweets: Bonding around the Bean on Twitter", in Seargeant, P. and Tagg, C. (eds.), The Language of Social Media: Identity and Community on the Internet, Basingstoke, Palgrave Macmillan, pp. 139-160.

2018 Searchable Talk: Hashtags and Social Media Metadiscourse, London, Bloomsbury.

2019 "Ambient Affiliation and \#Brexit: Negotiating Values about Experts through Censure and Ridicule", in Koller, V., Kopf, S. and Miglbauer, M. (eds.), Discourses of Brexit, London and New York, Routledge, pp. 48-68.

Zappavigna, Michele and Martin, James R.

2018 "\#Communing Affiliation: Social Tagging as a Resource for Aligning around Values in Social Media”, Discourse, Context \& Media, 22, pp. 4-12, DOI: 10.1016/j.dcm.2017.08.001.

Zappavigna, Michele; Dwyer, Paul; Martin, James R.

2008 "Syndromes of Meaning: Exploring Patterned Coupling in a NSW Youth Justice Conference", in Mahboob, A. and Knight, N. (eds.), Questioning Linguistics, Newcastle upon Tyne, Cambridge Scholars Publishing, pp. 103-117.

Zhao, Sumin

2010 "Intersemiotic Relations as Logogenetic Patterns: Towards the Restoration of the Time Dimension in Hypertext Description", in Bednarek, M. and Martin, J.R. (eds.), New Discourse on Language: Functional Perspectives on Multimodality, Identity, and Affiliation, London, Continuum, pp. 195-218. 


\section{Ocula}

Vol 21, No 22 (April 2020) • DOI: 10.12977/ocula2020-7

Giuseppe Balirano | Of Rainbow Unicorns. The Role of Bonding Queer Icons

in Contemporary LGBTIQ+Re-Positionings

2011 Learning Through Multimedia Interaction: The Construal of Primary Social Science Knowledge in Web-Based Digital Learning Materials, Unpublished Doctoral Dissertation, Sydney, University of Sydney.

Giuseppe Balirano, $\mathrm{PhD}$ in English Linguistics, is Professor of English Linguistics and Translation at the University of Naples "L'Orientale" and member of the PhD board in Language and Communication at the University of Catania. His research interests and publications lie in the fields of multimodal critical discourse analysis, humour, masculinity and queer studies, the discursive representation of organised crime and audio-visual translation. He is the Director of the interuniversity research centre, $I$-LanD, for the linguistic investigation of identity and diversity in discourse. He is the BeTwiXt series director, publishing original works in the field of linguistics and communication studies. His most recent publications include: Food Across Cultures: Linguistic Insights in Transcultural Tastes (2019, co-edited with S. Guzzo); Miss Man: Languaging the Gendered Body (2018, co-edited with O. Palusci); Self-Narratives in Organizations: Transgender and Gender Non-Conforming Experiences (2018, co-edited with P. Valerio and L.M. Sicca); Queering Masculinities in Language and Culture (2018, co-edited with P. Baker); Gardaí \& Badfellas: The Discursive Construction of Organised Crime in the Irish Media (2017); Humosexually Speaking: Laughter and the Intersections of Gender (2016, co-edited with D. Chiaro); Languaging Diversity (2015, co-edited with M.C. Nisco); and Masculinity and Representation: A Multimodal Critical Approach to Male Identity Constructions (2014). 